\begin{tabular}{|l|l|l||}
\hline \multicolumn{2}{|c|}{ PublisherInfo } \\
\hline \hline PublisherName & $:$ & BioMed Central \\
\hline \hline PublisherLocation & $:$ & London \\
\hline \hline PublisherImprintName & $:$ & BioMed Central \\
\hline \hline
\end{tabular}

\title{
Life cycle control of Chlamydomonas reinhardtii
}

\begin{tabular}{|l|l|l||}
\hline \multicolumn{2}{|c|}{ ArticleInfo } \\
\hline \hline ArticleID & $:$ & 4759 \\
\hline \hline ArticleDOI & $:$ & $10.1186 /$ gb-spotlight-20030423-01 \\
\hline \hline ArticleCitationID & $:$ & spotlight-20030423-01 \\
\hline \hline ArticleSequenceNumber & $:$ & 111 \\
\hline \hline ArticleCategory & $:$ & Research news \\
\hline ArticleFirstPage & $:$ & 1 \\
\hline \hline ArticleLastPage & $:$ & 2 \\
\hline \hline & & RegistrationDate : 2003-4-23 \\
\hline ArticleHistory & $:$ & OnlineDate \\
\hline \hline ArticleCopyright & $:$ & BioMed Central Ltd2003-4-23 \\
\hline \hline ArticleGrants & $:$ & \\
\hline \hline ArticleContext & $:$ & 130594411 \\
\hline \hline
\end{tabular}




\section{L Bishop}

Email: cleo.bishop@ic.ac.uk

In the unicellular alga Chlamydomonas reinhardtii nitrogen starvation triggers signal transduction pathways that result in entry in to a cycle of sexual reproduction. A second signal cascade is triggered by blue light, and results in the completion of gametogenesis. Two photoreceptors that respond to the blue region of the spectrum have been identified in $C$. reinhardtii; they are encoded by the phototropin and cryptochrome genes Phot and $\mathrm{CPH}$, respectively. In April 21 PNAS, Kaiyao Huang and Christoph Beck at The University of Freiburg, Germany examined the role of phototropin in the control of the sexual like cycle of Chlamydomonas reinhardtii. They showed that diminished phototropin levels affect all three light-dependent stages of the sexual life cycle of this alga.

Huang and Beck generated a Phot RNA interference (RNAi) knockdown mutant with transformants expressing only $10 \%$ of wild-type levels of Phot. When assayed, the mutant had reduced levels of conversions of pre-gametes to gametes. Expression analysis of the late-stage gametogenesis genes revealed reduced mRNA levels in the RNAi algae, indicating that phototropin serves as the photoreceptor for the induction of these genes. Examination of the reactivation of dark-activated RNAi and wild-type gametes by illumination suggests that phototropin also functions in the restoration of gamete mating ability. Furthermnore, zygotes generated from wild-type and RNAi gametes were subjected to light-induced germination. The degree of zygote germination was distinctly lower when RNAi gametes were used, suggesting that Phot also mediates light-induced zygote germination. The authors propose that phototropin is the photoreceptor that controls the blue-light-dependent sexual differentiation of $C$. reinhardtii.

"Because the reactivation of dark-inactivated gametes does not require protein synthesis, it has been hypothesized that blue light activates proteins of the flagella involved in sexual agglutination by some chemical modifications. This finding opens up the opportunity to analyze the consequences of phototropin activation in flagella, i.e., a system of reduced complexity," co nclude the authors.

\section{References}

1. Signal transduction in the sexual life of Chlamydomonas.

2. PNAS, [http://www.pnas.org]

3. University of Freiburg, [http://www.uni-freiburg.de]

4. Characterisation of blue light signal transduction chains that control development and maintenance of sexual competence in Chlamydomonas reinhardtii.

This PDF file was created after publication. 